\title{
Nas trincheiras da disfunção temporomandibular: estudo de vivências
}

\author{
At the forefront of the temporomandibular dysfunction: \\ a study of experiences
}

Alexandre Cardoso Rota (https://orcid.org/0000-0001-7221-7653) ${ }^{1}$

Emília Carvalho Leitão Biato (https://orcid.org/0000-0002-4358-4558) ${ }^{1}$

Sérgio Bruzadelli Macedo (https://orcid.org/0000-0002-5417-4239) ${ }^{1}$

Aline Cardoso Rota Moraes (https://orcid.org/0000-0002-5901-5229) ${ }^{1}$

${ }^{1}$ Universidade de Brasília.

Campus Universitário

Darcy Ribeiro s/n, Asa

Norte. 70910-900 Brasília

DF Brasil.

alexandrerota2@gmail.com

\begin{abstract}
How does one address an ailment related to such unique experiences without dissociating it from relationships, living conditions and society? Temporomandibular Disorder (TMD) is one of a group of chronic disorders that are difficult to diagnose and provide treatment. As in other similar ailments, such difficulties may accentuate a negative impact on health. The study seeks to identify experiences of health service users with TMD, aiming to contribute to reflection and management practices for the issue. A qualitative otobiographical study was developed, using interviews with people undergoing TMD treatment. Based on the Nietzschean premise that the process of subjectivation is fed by experiences, the method seeks to identify traces of these experiences through the texts resulting from the interviews. Patients' experiences were grouped into five categories: recognition; frustrations; concealment; sadness, fear and death; and destinies. A variety of negative effects have been described in the first three stages, whereas the last one, namely destinies, elicits feelings of well-being. The value of the interactive (professional-user) space, which expresses itself as the power to create innovative and sensitive ways of dealing with health-disease processes, needs to be highlighted.
\end{abstract}

Key words Pain, Temporomandibular Disorder, Experiences, Philosophy of health, Autobiographical research
Resumo Como abordar uma doença que traz vivências tão singulares e fazê-lo sem dissociações com as relações, as condições de vida e sociedade? A Disfunção temporomandibular (DTM) é um grupo de desordens crônicas difíceis de diagnosticar e prover tratamento. Como em outras doenças similares, tais dificuldades podem agravar o impacto negativo sobre a saúde. O estudo busca identificar vivências de usuários de serviços de saúde com DTM, visando contribuir com as práticas de reflexão e manejo para a questão. Foi desenvolvido um estudo qualitativo, de caráter otobiográfico, a partir de entrevistas com pessoas em tratamento de DTM. Parte-se da premissa nietzschiana de que o processo de subjetivação é alimentado por vivências; portanto, o método busca a identificação de traços dessas vivências nos textos produzidos a partir da transcrição das entrevistas. As vivências dos pacientes foram agrupadas em cinco trincheiras: nomeação; frustrações; escondido; tristeza, medo e morte; e destinos. Uma variedade de efeitos negativos foi descrita através dos três primeiros estágios, enquanto em destinos, emergem as sensações de bem-estar. Destaca-se o valor do espaço profissional-usuário, que expressa a potência de criação de modos inovadores e sensíveis de lidar com os processos de saúde-doença.

Palavras-chave Dor, Disfunção temporomandibular, Vivências, Filosofia da saúde, Pesquisa autobiográfica 


\section{Introdução}

A trincheira é o espaço que se tenta fazer seguro, firme, estratégico. Espaço de combate, da luta inevitável e improrrogável ${ }^{1}$. Parece ser uma imagem próxima às vivências de pessoas que apresentam disfunção temporomandibular (DTM), pois buscam lugares seguros, respostas precisas e indícios de estratégias possíveis de reversão ou melhor convivência com o problema de saúde.

A Associação Americana de Pesquisas Odontológicas define DTM como um grupo de condições musculoesqueléticas e neuromusculares que envolvem as articulações temporomandibulares, músculos mastigatórios e tecidos associados, de forma patológica. Por se caracterizar como uma condição complexa, prover soluções adequadas permanece um desafio, tanto para os que sofrem da doença quanto para os clínicos ${ }^{2,3}$.

Destaca-se a dificuldade de conviver com essa condição crônica, que acompanha o indivíduo durante anos, um percurso que leva as pessoas envolvidas a posicionarem-se em diversas trincheiras: sensações de corpo e alma, enfrentamentos, buscas, perguntas. Um ponto crítico está em obter um adequado diagnóstico - um nome para o infortúnio -, pois, em sua ausência, são auferidas distintas terapias, por vezes frustrantes. Os percursos belicosos, por vezes, arrebatam o ser a dissimular e viver sua tristeza e medo às escondidas dos que ama ${ }^{4}$.

Entender as experiências vividas por estes pacientes - quais sentimentos afloram, que dificuldades enfrentam singularmente, como ocorrem os processos de subjetivação nesse contexto, expectativas e o que demandam - torna-se relevante para que se possa compreender suas necessidades e criar maneiras mais eficientes para oferecer-lhes atenção à saúde de forma plena, produzindo um novo destino 5 .

Portanto, este estudo busca identificar as vivências de usuários de serviços de saúde com disfunções temporomandibulares, incluindo seus sofrimentos, expectativas e vivências, visando contribuir com os processos de comunicação e atenção à saúde entre usuários, cirurgiões dentistas e outros profissionais da saúde, nas melhores práticas de manejo para a questão.

\section{A dor, a doença e seus percursos}

"A expressão dor orofacial (DOF) está ligada à dor presente em tecidos moles e mineralizados da cavidade oral e da face. Essa dor pode ser referida na região da cabeça e/ou pescoço ou mesmo estar associada a outras patologias $»^{6}(\mathrm{p} .114)$. A DTM é uma das mais frequentes causas de dor orofacial. A prevalência de DTM na população é de $10 \%$ a $15 \%$, com maior incidência na faixa dos 20 a 40 anos, apresentando uma distribuição superior no sexo feminino de aproximadamente $2: 1$. A dor associada à DTM crônica é pouco esclarecida pelos achados físicos e de imagens relevantes ${ }^{7}$.

Trata-se de uma doença que traz sofrimento aos pacientes e que é de difícil obtenção dos oportunos diagnóstico e tratamento, fazendo com que os acometidos tracem um longo itinerário de busca de múltiplos profissionais antes de obter um adequado desfecho ${ }^{4}$.

A literatura da área odontológica apresenta diversas narrativas dos acometidos por DTM, enfocando a dor em si e a experiência de viver com a sensação de demasiada incerteza. São angústias devidas às dores è̀s dificuldades com o diagnóstico; preocupações acerca da automedicação descontrolada, redução da qualidade de vida e, por fim, a fase depressiva, com perda de esperança e tentativa de fuga da realidade ${ }^{8}$.

Ainda, Costa et al. ${ }^{9}$ afirmam que a má qualidade de vida - muitas vezes envolvendo a experiência diária -, a necessidade de medicação constante, o medo e a sensação de proximidade de um fim à existência, habitam o pensamento dos que sofrem com a DTM, fazendo oposição e dificultando a chegada ao momento do diagnóstico e do tratamento adequados.

Um ciclo se inicia quando os usuários de serviços de saúde começam a perceber que as diferentes manifestações constatadas estão associadas entre si, ao que partem em uma busca para descortinar as causas e soluções. O estado de adoecimento é assumido pelo paciente, contudo, nem sempre é reconhecido de imediato pelo clínico. Instala-se a incompreensão de quem sente as manifestações, mas não constata correspondência na arte médica, trazendo consigo a sensação de não ter o direito à saúde, e de que é preciso sempre se enquadrar no rol do cientificamente explicável, tensão que não passa incólume aos doentes ${ }^{4,10}$.

Destaca-se o cuidado centrado no procedimento: com foco em especialidades, os serviços acabam por fragmentar o indivíduo em diversos expedientes técnicos que não necessariamente estão unidos entre si, o que dificulta a compreensão e a participação ativa do sujeito no processo de construção, desenvolvimento e avaliação das práticas ofertadas ${ }^{8}$.

Instala-se, no encontro profissional-paciente, um conflito pela urgência e simultânea dificuldade 
de encontrar uma explicação. O profissional da Saúde procura, na associação entre seus conhecimentos científicos, sua experiência clínica e o contato direto com a queixa do paciente, dar um nome ao que se lhe apresenta.

A combinação/confusão de discursos torna-se um empecilho, à medida em que não se encontram relações imediatas entre o conjunto de sintomas e o nome de um diagnóstico que o defina plenamente. Por outro lado, justamente essa $b a$ belização expressa a complexidade e a riqueza dos processos de saúde-doença, ampliando o modo de percebê-los ${ }^{11}$.

"Torres, giros, voltas, circunlocuções, viagens, passeios, vias, peças, vezes, tornos, truques, e até mesmo desvios se confundem na confusão de Babel"11(p.8). Sabe-se que o discurso - assim como a escrita - tem uma potência para o desvio, para seguir um rumo pouco previsível e chegar de formas diversas a destinos impensados ${ }^{11}$. No contexto do sofrimento de pessoas com DTM, essa errância chega de forma angustiante, com muitas incertezas acerca dos destinos da vida mesma.

Nota-se, nos espaços clínicos ou coletivos de atenção à saúde, a existência de um processo tradutório. Há uma série de termos utilizados pelos usuários dos serviços de saúde, que estão distantes da terminologia científica com a qual o profissional costuma lidar. E o contrário também. Nesse contexto, como traduzir o que se sente, chegar a um diagnóstico, estabelecer o melhor tratamento e realizar tudo isso de forma democrática, eficiente e partilhada? Permanece a questão levantada por Derrida: "Como traduzir um texto escrito em diversas línguas ao mesmo tempo? Como devolver o efeito de pluralidade? E se se traduz para diversas línguas ao mesmo tempo, chamar-se-á a isso traduzir"12.

$\mathrm{O}$ emissor (usuário ou algum parente, em seu nome) elabora um discurso na direção do profissional buscado, apresentando o tamanho e as características de sua dor; faz pedidos, esforçando-se para ser claro o suficiente para que o destinatário (profissional da saúde) receba suas necessidades, e tenha a capacidade de satisfazê-las ${ }^{13}$. Lembra-se, aqui, que "a riqueza do que se vive é traduzida e inscrita em nomenclaturas bem delimitadas e o discurso médico não parece tolerar ambiguidades" ${ }^{14}$. A relação profissionalpaciente funciona como processo de tradução, que não é sempre harmônico, pois compõe-se de pluralidades.

Nesse sentido, torna-se relevante que os profissionais de saúde desenvolvam a capacidade de ampliar perspectivas acerca do processo saúde- doença, incluindo palavras variadas, observação minuciosa, atenção e sensibilidade. Importa, especialmente na lida com as DTMs, assumir a complexidade da experiência de adoecer, das vivências de quem sente a dor e de quem está envolvido, da relação profissional-paciente, dos diagnósticos e das terapias existentes.

É nesse contexto que toma-se, do filósofo alemão Friedrich Nietzsche ${ }^{15}$, a noção de vivências, em uma apropriação que favoreça o pensamento sobre o vivido por pessoas com DTM.

\section{Das vivências em Nietzsche}

O termo vivências encontra-se espalhado pela obra de Nietzsche, com pequenas explicações e diversos usos de seu conceito. A noção de vivências pode ser tomada, em primeiro lugar, como afirmação do constante processo de vir a ser no qual nos encontramos. Essa noção de inacabamento expressa a vida como movimento contínuo de tornar-se.

Entende-se que não há modos de alcançar o ideal da saúde plena, assim como cada sujeito não existe em completude. A noção de morte da metafísica platônica, com a morte de Deus, traz consigo a impossibilidade da identidade como entidade. Abre-se mão da noção do ser como ente completo e estabelece-se a vida como constituição de si, sempre em vias de fazer-se ${ }^{15}$.

A compreensão do conceito de vivências está relacionada à noção de vontade de potência. Deleuze ${ }^{16}$ discute a vontade de potência como "um querer interno”, que está em todos os seres. É um desejo de afirmação da vida, do modo como ela se apresenta, não negando suas dores e mazelas. Assim, a vontade de potência pode ser entendida como uma força entre outras que compõem nosso corpo, e que atua definindo quais serão as configurações das ligações entre esses vetores, conforme notável em Deleuze ${ }^{16}$ : "A vontade de potência é o elemento de onde dimanam simultaneamente a diferença de quantidade das forças postas em relação e a qualidade que, nessa relação, marca cada força" ${ }^{16}$ (p.77).

Assim, a vontade de potência impulsiona as forças que, então, circulam, a princípio, sem sentido e, portanto, abertas a diferentes possibilidades: qualquer sentido pode ser atribuído às forças pela vontade ${ }^{16}$. A vontade de potência como vontade orgânica comum a todo ser vivo e exercida no corpo: "nos órgãos, tecidos e células, nos numerosos seres vivos microscópicos que constituem o organismo" 17 . As forças se associam 
e se desagregam, "em fluidez de forma e sentido"18(p.88). Algumas triunfam e tomam a palavra, sobressaindo na efetividade do ser, enquanto outras perdem temporariamente. Importa dizer que o combate é incessante e é, justamente esse movimento que garante a incompletude, a impossibilidade de absolutizar a noção de sujeito. Justamente a luta de forças é o que cria diferentes estilos de individuação $0^{15}$. Afirma-se, assim, a diversidade dos seres humanos, que estão sempre em processo de mudança.

Nesse contínuo movimento de tornar-se, as vivências se apresentam como alimento. Ou seja, as vivências - que podem ser situações ordinárias ou extremamente significativas - são fisgadas por determinadas forças que compõem o corpo, tornando-as robustas e prevalentes. Simultaneamente, outros vetores se enfraquecem, definham, sofrem de inanição, ainda que sobrevivam ${ }^{19}$ abrindo possibilidades aos processos de criação e invenção de si.

Biato $^{20}$ compreende a grande saúde nietzschiana como criação de si, como percorrer uma "via de alegria e sofrimento, com inventividade, interpretação, performance"20(p.99). Pode-se afirmar, portanto, que as vivências de quem sofre com DTM servem de alimento para forças constituidoras desse corpo que segue vendo a saúde escapar, perde, ganha esperança, nutre o que lhe falta e traça, assim, seu movimento de tornar-se o que é.

\section{Materiais e métodos}

Com interesse em tomar as vivências de pessoas com DTM como objeto de pesquisa, vimo-nos diante da questão de como abordar o percurso incerto de tornar-se o que se é. Como tratar do que se experimenta tão singularmente e, ao mesmo tempo, coletivamente ${ }^{21}$ ? Que caminhos chegariam aos traços do vivido? Como se aproximar da incerteza e da dor do outro? Como abordar as ansiedades no cotidiano de quem sofre de uma doença crônica, e tem de sorrir, trabalhar e conviver socialmente, sem saber se tomará conhecimento do que realmente a aflige, nem qual a expectativa futura para o agravo.

Pacientes previamente admitidos como portadores de DTM foram encaminhados ao projeto de DTM de um Hospital Universitário, onde foram submetidos por profissionais devidamente treinados ao questionário Research Diagnostic Criteria for Temporomandibular Dysfunctions (RDC-TMD), sendo selecionados os que se en- quadraram em um dos seguintes diagnósticos do Eixo I definidos pelo RDC/TMD para DTM: dor miofascial (Ia), dor miofascial com abertura limitada (Ib), deslocamento de disco com redução $(\text { IIa })^{22}$.

O RDC/TMD é um instrumento de diagnóstico e pesquisa que permite uma avaliação multidimensional da dor advinda da DTM, incluindo métodos para classificação física dos diagnósticos (Eixo I), e métodos para avaliar a intensidade e severidade da dor crônica e os níveis de sintomas depressivos e físicos não-específicos (Eixo II ${ }^{23}$.

Todos os pacientes foram confirmados como portadores de Disfunção Temporomandibular, eram maiores de 18 anos e apresentavam relatos de sinais e sintomas de DTM há pelo menos 6 meses.

Os pacientes foram então tratados no projeto de disfunção temporomandibular (DTM/HUB) do Hospital Universitário de Brasília, utilizando técnicas cientificamente aceitas e consideradas padrão ouro para DTM, ao longo do período de 24 meses. Ao final do tratamento, de um total de 37 participantes, 32 - sendo 28 mulheres e 4 homens - foram entrevistados através de instrumento semi-estruturado, com roteiro previamente definido e flexibilidade de respostas, compondo um diálogo que permitisse a expressão das subjetividades.

Importa destacar que o estudo foi aprovado por Comitê de Ética em Pesquisa da Faculdade de Ciências da Saúde da Universidade de Brasília (UnB), e respeitou seus princípios. Entrevistamos apenas as pessoas que entenderam a proposta da pesquisa e assinaram o termo de consentimento livre e esclarecido, que inclúa a necessidade de videogravação. As entrevistas foram realizadas em espaço reservado, no ambiente da clínica odontológica do hospital, sem interferências de outras pessoas e com o cuidado de tempo e espaço, para que os participantes não assistissem às entrevistas uns dos outros. Todos os nomes adotados são fictícios, garantindo o anonimato dos participantes da pesquisa.

Foram destacadas assim, as experiências vivenciadas desde o início dos sintomas até o momento da entrevista. Tais entrevistas foram filmadas e assistidas integralmente pelos pesquisadores. Os trechos que pareceram relevantes de acordo com o objetivo de analisar traços de vivências ligadas à DTM e aos seus tratamentos foram transcritos, constituindo pequenos textos.

Compreende-se que vivências distintas desenvolvem diferentes modos de lidar com a doença, tornando-a absolutamente singular. Foi com 
o método otobiográfico, que a atenção voltou-se para os textos ${ }^{24}$. Esse método foi desenvolvido a partir da noção nietzschiana de vivências e do conceito de "otobiografias" proposto por Jacques Derrida $^{25}$ no livro de mesmo nome. Trata-se de tomar, em mãos, a obra grafada e percorrê-la como um labirinto, aguçando os ouvidos aos traços do vivido.

Otobiografia se configura, portanto, como uma escuta de biografias. Das vivências que tracejam as narrativas, das forças que as movimentam, as criações que levam cada relato a uma assinatura pessoal. Trata-se de tomar, em mãos, a obra grafada e percorrê-la como um labirinto, aguçando os ouvidos aos traços do vivido. $\mathrm{Ou}-$ vir as vivências é ação-sensação do pesquisador, conforme a afirmação nietzschiana de que "não se tem ouvido para aquilo que não se tem acesso a partir da experiência”"15(p.53).

\section{Das vivências com DTM}

As vivências foram divididas em quatro trincheiras ou barreiras, pretendendo dar uma cronologia a esta jornada pelo desconhecido, que não obedece, necessariamente, às normas cronológicas, uma vez que são fenômenos que vão e vem, que se misturam e se alimentam.

Chamamos de trincheiras, com inspiração no trabalho de Costa ${ }^{1}$, e por termos a noção da luta de forças em ocorrência na vida de cada sujeito deste estudo, bem como dos pesquisadores. Luta no constante movimento de tornar-se o que se é, e no sentido das dificuldades travadas em torno da dor, da experiência de adoecer e de seus efeitos sociais, físicos e psíquicos.

Nesse sentido, as trincheiras se sobrepõem, iniciando nas adversidades da doença e a privação de um adequado diagnóstico, passando por uma tentativa de reduzir o sofrimento, de melhorar sua experiência e um desfecho, talvez a alegria de uma adequada terapêutica, quiçá a renúncia e a falta de esperança, por não obter uma cura.

As trincheiras destacadas foram: 1. Nomeação; 2. Frustrações; 3. Escondido; 4. Tristeza, medo, morte; 5 . Destinos.

\section{Nomeação}

Eram muitas dores que eu tinha assim, não me queixava muito, ficava quieta no meu canto [...] tinha dor direto, direto, para dormir... todos os dias sentia dores muito fortes [...] tudo que você imagina de especialidade [médica/odontológica], eu busquei. (Teresa).

Faz mais de 50 anos com uma dor de cabeça constante, todos os dias, era remédio e remédio, fui em médicos, especialistas, nunca acharam nada. (Oto).

Dor de cabeça, náusea, vômitos constantes, que não tinha o que parasse, não tem tratamento [...]; tudo já procurei, todos os médicos possíveis. (Priscila).

É notória a percepção nos relatos, que a principal experiência física da DTM é a dor, e que a procura por cuidados é, muitas vezes, frustrante, sendo esta vivência ainda mais intensa. Dores de cabeça, sintomas otológicos, nas costas, travamento da mandíbula, entre outros sintomas dificultam a compreensão de tratar-se de uma mesma causa ${ }^{3,6}$.

Os pacientes convergem quanto à queixa de experimentar uma situação que chega aos poucos, dia após dia, e permanece por longo prazo. Principia aí, a peregrinação em busca de uma solução para o problema: diversos profissionais e especialidades, inúmeros exames, reduzidas respostas.

A dificuldade de chamar o problema por um nome se traduz como o que não se pode pegar. Como uma perda contínua e, intangível, a DTM demora a permitir um luto e a lida com as configurações da vida. Nietzsche ${ }^{26}$ usa a noção de tragédia da arte grega para dizer do quanto a vida escapa e são impossíveis as fixações. O tempo todo estamos em movimento de vir a ser, nunca totalmente acabados e prontos - nunca há um resultado tangível que configure o vivente em completude. As vivências com a DTM parecem um exagero do que não chega, do que não é possível alcançar, do que se perpetua inacabado, como nota-se nas expressões "tudo já procurei" e "nunca acharam nada".

Vários estudos demonstram a dificuldade dos clínicos em diagnosticar e tratar as DTMs, o que é causa de insatisfação para os doentes e constrangimento para os profissionais. A principal queixa dos doentes é a de receberem explicações parciais ou inadequadas quanto a seus sintomas, enquanto seus exames apresentam resultados inconclusivos ${ }^{4,7}$.

Parece ser essa a sensação de falta de caminho e de possibilidades, como uma força que retira dos nossos olhos o horizonte. Tanto Oto quanto Priscila dizem da incerteza diante da falta de legitimação do que se passa, de qual é a doença que traz consigo a angústia de um futuro incerto. A ausência de um nome, de uma explicação palpável quanto ao motivo de tanto infortúnio levam à insegurança no ambiente profissional, pessoal e familiar, minando a credibilidade do enfermo. 
A busca por vários profissionais acaba por expressar o desejo por um nome, para que este dê alento e perspectiva. As ciências médicas, de fato, operam pela lógica da nomeação e do registro de achados e manifestações no corpo. A dificuldade de enquadrar as sensações experimentadas nesse conjunto de nomes traz a angústia, como se aquilo que não se pode nomear, de fato, nem existisse.

$\mathrm{Na}$ inexistência do diagnóstico e portanto de um possível tratamento, as manifestações psicológicas, como a introspecção e recolhimento, são comuns, com impacto ainda mais negativo na saúde. O sujeito evita exprimir suas queixas para outrem, suportando em silêncio as sequelas da morbidade em suas atividades, e conviver com a ansiedade de não saber o que virá a seguir ${ }^{27}$.

O trecho nietzschiano traz uma luz a esse desejo de nomear o que se vive: "necessitamos de pontes, de experiências, de vivências. Então, necessitamos dos seres humanos, que as interpretem para nós, que as expressem..." ${ }^{28}$. Os seres humanos interpretam vivências e as expressam. Vivências partilhadas abrem pontes que permitem acessar acontecimentos difíceis de digerir. O profissional da Saúde, nesse contexto, pode desenvolver um papel relevante na aproximação com o que o outro experimenta. Poderá partilhar tanto as dores quanto o alento, contribuindo para a produção da saúde.

\section{Frustrações}

Sentia dor o tempo todo, não conseguia falar com ninguém, não quería ver ninguém. (Laura).

Eu me emociono toda vez que lembro de não poder brincar com meu filho, não podia sair, marcar compromisso. (Fábio).

As dores me atrapalhavam na convivência, no trabalho, na qualidade de vida [...]; às vezes tinha que ir ao hospital, a dor era insuportável. (Luísa).

Uma vez iniciado o círculo vicioso, no qual nem profissional, nem usuário do serviço conseguem nomear o problema, os doentes acometidos pelas dores recorrentes, problemas psicológicos e demandas diárias em busca de alívio, oscilam constantemente entre a esperança e o desespero $^{27}$. Em alguns momentos, convencidos de que não encontrarão a causa de suas queixas, em outros, estão certos de que o passar do tempo trará avanços e a ciência auxiliará nas respostas as quais busca ${ }^{29}$.

Fábio aponta para as frustrações em seu dia -a-dia: incapaz de contornar os obstáculos impostos pela enfermidade, deixa de empreender mesmo as mais simples atividades, perdendo momentos inestimáveis. Além dos sinais e sinto- mas que resultam em um declínio laboral e social, vê-se diante da necessidade de ser internado e abordado com intervenção farmacológica.

Chega-se ao ponto extremo da resignação e encolhimento: o momento fatal de não querer ver ninguém, falar com ninguém, da falta de sentido em viver, como notável na afirmação de Laura.

Há coisas na vida que, sabidamente e sensitivamente, valem a pena, como marcar e comparecer a um compromisso, como brincar com o filho, como falar com alguém, como olhar e poder ver, sem se recolher no escuro. Essas experiências perdem seu brilho e seus efeitos diante da dor. A vida perde sua potência, se encolhe, se esvai. Ao tratar das forças plásticas, Nietzsche ${ }^{28}$ afirma:

Há homens que possuem tão pouco esta força que, em uma única vive ncia e uma única dor, freqüentemente mesmo em uma única e sutil injustiça, se esvaem incuravelmente em sangue como que através de um pequenino corte; por outro lado, há homens nos quais os mais terriveis e horripilantes acontecimentos da vida ... afetam tão pouco, que os levam em meio deles ou logo em seguida a um suportável bem-estar e a uma espécie de conscie ncia tranqu ila ${ }^{28}$.

Forças plásticas relacionam-se com a capacidade de tomar-se em mãos e se restabelecer, pois são "curativas, reconstrutoras e restaura$\operatorname{doras}{ }^{30}$ (p.9). Ainda que não finde o problema, uma força plástica estica o corpo até a persistência e a resiliência. Muitas dores empurram para o abismo as possibilidades de mobilizar forças plásticas, flexíveis, resistentes. A vida vai perdendo sua potência de célula indiferenciada - força para ser o que se deseja - para, simplesmente, respirar. A manutenção das funções vitais torna-se penosa demais e a dor dita o ritmo da vida. Vida que sofre mais do que pensa ser capaz. Vida que se encolhe diante da dor. Dor que afugenta e leva consigo as forças.

\section{Escondido}

Tomava medicamentos com frequência, anti -inflamatórios eu conheço todos [...] era internada a cada 6 meses, com Morfina. (Ana).

Tomava tudo que achava bom, [...] de manhã, à tarde, de noite, e no outro dia tomava tudo de novo. (Fernanda).

Tomava medicamento com muita frequência, cada horário tinha um remédio, [...] foi quando fiquei sabendo que um dos rins eu estava quase perdendo, por excesso de medicação. (Priscila).

Os entrevistados têm seu corpo tomado pela presença da dor, mesmo nos momentos em que ela está ausente. Jaqueline Ferreira ${ }^{31}$, ao abordar 
os discursos sobre a dor e o uso dos signos, traz um trecho que parece pertinente aos casos abordados aqui: "Ela não se queixa de dor por causa dos remédios fortes que eles dão, mas a dor tá ấ” ${ }^{31}$ (p.107). A sanidade e a doença parecem habitar, simultaneamente o corpo, sendo impossível discernir os limites de uma e outra - coabitação de linguagens ${ }^{32}$.

O corpo de quem sofre com a DTM experimenta essa coabitação de linguagens: em momentos de calmaria, atiça células, tecidos, órgãos e sistemas, tentando planejar a abordagem da próxima crise, na angústia de saber o que os espera em breve.

Como observamos nas narrativas, os pacientes adotam, como medida de tratamento, a terapia farmacológica, ingerindo inicialmente analgésicos a que tenham acesso. Contudo, o efeito dos mesmos tende a ser insuficiente, e o aumento da dose ou uso concomitante com outros medicamentos é um caminho comum, quase sempre sem a devida prescrição profissional ${ }^{33,34}$.

Relatam ainda fazê-lo às escondidas de seus entes próximos, que reprovariam tal conduta, em um claro sinal de descrença em relação a sua situação e seu desenvolvimento, como se somente o presente importasse.

Fernanda, Priscila, Ana e tantos outros parecem sofrer, então, sós. Nem quem com elas reparte o mesmo prato consegue se aproximar do que sofrem, sentem, tornam-se a cada dia. Dor agora e depois. Imprevisível, embora certa.

\section{Tristeza, medo, morte}

Tenho um tumor no cérebro, fui ao cardiologista porque achava que estava tendo um infarto. (Beatriz).

Fazia exames e ficava preocupada, pois não achava nada, achava que era mais grave ainda; eu tinha medo de dormir e acontecer alguma coisa comigo dormindo. (Laura).

[...] ficava apreensiva [...] às vezes pensava no pior. (Selma).

Já tinha na minha mente que nunca ia ter uma cura, ia morrer disso. (Márcia).

Diante do desassossego experimentado por serem tratados como pacientes difíceis, com afirmações profissionais de que suas dores seriam fruto de somatização, estresse, e mesmo imaginação, muitos começam a desenvolver suas próprias teorias para o problema.

Absortos em seus pensamentos, os desafortunados têm a sensação de que as pessoas ao seu redor não acreditam nos seus relatos; são rotuladas como se estivessem apenas simulando tal situação, dificultando a determinação do limite entre saúde e doença, de sua sanidade não só física, mas também mental ${ }^{35}$.

Isto se traduz de forma abundante na exacerbação dos sintomas, gerando ainda mais apreensão na formulação de hipóteses de quem sofre de doença grave ou incurável e, diante do inapropriado tratamento a conclusão é de que aquilo acabará por ceifar-lhe a existência.

Assim, o sofrimento convoca para perto do fim, para as feições da morte. Torna-se familiar. Tão familiar, que Nietzsche resolve dar à sua dor o nome de Cachorro - "Mi dolor es tan fiel, discreto y desvergonzado como mi perro, y su companhia me divierte igual..." ${ }^{36}(\mathrm{p} .12)$. De modo semelhante, Frida Kahlo teve um cachorro chamado "Dolor": "su dolor no la vuelve muda, su grito es un aullido articulado porque alcanza una forma visible y emocional" ${ }^{36}$ (p.12).

Também Antonin Artaud relata sua falta de paz e dificuldade de sentir-se vivo:

O eletrochoque me desespera, tira minha memória entorpece meu pensamento e meu coração, transforma-me num ausente que se percebe ausente e se vê durante semanas perdido em busca de seu ser como um morto ao lado de um vivo. $\mathrm{Na}$ última se rie eu fiquei durante todo o mês de agosto e setembro absolutamente impossibilitado de trabalhar, de pensar e de me sentir ser. Peço que me poupe de uma nova dor, isto me fará repousar, Dr. Ferdie re, e preciso muito de um repouso ${ }^{37}$ (p.190).

A sensação de que "ainda vou morrer disso" ou "tenho um tumor no cérebro" parece ter funcionado, como vivências que chamam à dúvida sobre a vida, sobre o "sentir-se ser", afirmando a companhia da morte na rotina. Difícil conciliar o sono e a paz diante de uma condição como essa.

\section{Destinos}

Nunca tinha dado um sorriso pro doutor, agora estou aqui sorrindo. (Elisangela).

Nossa, agora tá maravilhoso! [pós tratamento]. (Fernanda).

Tudo mudou, parece mentira que era tudo dos dentes, [...] minha vida está muito melhor. (Teresa).

Encontrar um profissional que execute um adequado diagnóstico é momento singular para os portadores de DTM: descobrir o motivo de seus sintomas, receber uma definição de sua doença, de menor gravidade do que muitas vezes imaginaram, e ter acesso a um tratamento eficaz ${ }^{2}$.

Os pacientes passam a desfrutar de singelos momentos que pareciam irrecuperáveis. 
$\mathrm{Na}$ impossibilidade de resgatar o que passou ou de retornar à condição considerada normal anteriormente ao problema, criam-se novas formas de vida e saúde no mesmo corpo.

As vivências da dor e todo o sofrimento por ela gerado se juntam, modificam, transformam, constituem novos estilos de individuação. Nesse sentido, deixam marcas e apresentam o movimento de tornar-se o que se é. Há, nas expressões desse último tópico - Destinos - possibilidades para novos rumos, para se fazerem planos e retomar o futuro.

Moreira ${ }^{38}$ ao tratar de saúde-doença-terapêutica a partir de Nietzsche e Espinoza, aborda a importância de tomarmos a promoção da saúde como "uma arte de despertar potencialidades e de criação de novas formas ou modos de agir no mundo"38(p.159-160), processo que requer, do profissional, o afeto, o encontro, a sensibilidade em relação ao outro.

$\mathrm{Na}$ relação profissional-paciente, buscou-se superar o que está simplesmente nos manuais e tratados, para investir na aproximação com os modos de subjetivação de quem sofre e relata sua dor. Foi um movimento de apreensão e uso dos protocolos de forma criativa e dinâmica, de forma a não estabelecer fixações pouco efetivas de cuidado.

Buscou-se, diante das condições de vida com DTM, uma via de expansão da vida e da saúde, conforme vemos: "se, por um lado, uma saúde apequenada obedece a um script, uma grande saúde diz respeito à expansão da vida, que afirma seu caráter criador" 39 (p.973).

Nesse sentido, vemos, com Canguilhem ${ }^{40}$, a importância de que cada um estabeleça para si, parâmetros para poder afirmar se tem ou não uma boa saúde. Como vimos em alguns relatos, embora diversos exames não apontassem para nenhum diagnóstico, a dor permanecia ali:

O homem só se sente em boa saúde - que é, precisamente, a saúde - quando se sente mais do que normal, isto é, não apenas adaptado ao meio e às suas exigências, mas, também, normativo, capaz de seguir novas normas de vida ${ }^{40}$ (p.79).

A capacidade de ser normativo, para o autor, é justamente, encontrar a saúde: criar uma linguagem partilhada sobre as sensações, criar modos de lidar, viver e transformar o próprio corpo. Nesse sentido, o profissional de saúde tem um rico papel de parceria na arte de promover saúde.

\section{Considerações finais}

Os textos estudados apresentam indícios de vivências ligadas à dor temporomandibular. Passando pela angústia de nomear o que se vive - o encontro com o diagnóstico já parece trazer grande alívio e esperança -, pelos estados de tristeza, sofrimento e sentimento de morte, destacam-se elementos do que se pode classificar como máqualidade de vida e descrédito na cura. Estabelece-se um cenário de apatia, no qual a única certeza é a necessidade de sobreviver, ou um cenário de esperança de que a evolução da científica conduzirá a uma solução. O benefício no tratamento, nos relatos observados, pareceu relacionado a uma conduta positiva, de afirmação da vida, sem negar que esta inclui altos e baixos, dores e prazeres, a uma capacidade de manejar seu estado e de conviver em sociedade, de ser bem sucedido no manejo da doença, ou mesmo eliminá-la.

Diante das vivências colhidas e analisadas nesse estudo, entende-se que o ponto principal da terapêutica adotada localizou-se na atenção aos sinais manifestos, para um acertado diagnóstico e plano de tratamento, mas também na capacidade de oferecer uma resposta precisa e sensível, sem julgamentos e tentativas de moralização da saúde e da vida do outro.

A consideração de que cada um tem vivências singulares, mesmo que se enquadrem em um mesmo diagnóstico, significa um salto nos modos de cuidar, com potencial criador, tanto por parte do paciente - criar modos singulares de conduzir a vida com DTM -, quanto do profissional - criar modos individualizados de atuar junto aos pacientes, suas queixas, dores e possibilidades.

O método otobiográfico permitiu uma aproximação aos traços de vivências de pessoas com DTM, sem, no entanto, fixar relações lineares de causa e efeito, nem buscar o que está por trás do que se diz em cada momento. Permitiu relatos espontâneos, e portanto, elementos ricos para análise de pensamentos sobre o tema.

A análise trouxe elementos relevantes acerca das dificuldades encontradas nos itinerários do portador de DTM e enfatizou as vivências singulares nesse percurso, por vezes labiríntico. Abordou-se a necessidade de encontrar um nome para o que se tem, como se isso trouxesse esperança e controle. Ainda, foram discutidas frustrações, 
medos, tristezas e sentimentos de morte, bem como práticas escondidas e sentimentos de culpa, vergonha e inadequação. Por fim, foram tratados os destinos encontrados pelos sujeitos do estudo - pacientes com DTM e cirurgiões-dentistas - com valor ao espaço interativo, que se expressa como potência de criação de modos inovadores e sensíveis de lidar com os processos de saúde-doença, de forma partilhada, singular e efetiva.

\section{Colaboradores}

A idealização do projeto coube a AC Rota e ECL Biato, assim como a análise de dados e elaboração do texto. SB Macedo e ACR Moraes executaram a coleta de dados e revisão do artigo.

\section{Referências}

1. Costa LB. Ainda escrever. 58 combates para uma politica do texto. São Paulo: Lume Editora; 2017.

2. De Leeuw R. Orofacial pain: guidelines for assessment, diagnosis and management. $4^{\mathrm{a}}$ ed. Chicago: The American Academy of Orofacial Pain, Quintessence; 2008.

3. Yokoyama Y, Kakudate N, Sumida F, Matsumoto Y, Gordan VV, Gilbert GH. Dentist's distress in the management of chronic pain control: the example of TMD pain in a Dental Practice-based Research Network. Medicine 2018; 97(1):9553.

4. Durham J, Steele JG, Wassell RW, Exley C. Living with uncertainty: temporomandibular disorders. J Dent Res 2010; 89(8):827-830.

5. Kelleher M, Ray-Chaudhuri A, Khawaja N. Patients' Priorities and Attitudes Towards Their Temporomandibular Disorders. Dent J Prim 2015; 4(3):17-21.

6. Carrara, SV, Conti PCR, Barbosa JS. Termo do $1^{\circ}$ Consenso em Disfunção Temporomandibular e Dor Orofacial. Dental Press J. Orthod 2010; 15(3):114-120.

7. Ohrbach R, Dworkin SF. The Evolution of TMD Diagnosis: Past, Present, Future. J Dent Res 2016; 95(10):1093-1101.

8. Mângia E, Muramoto M. Itinerários terapêuticos e construção de projetos terapêuticos cuidadores. Rev Terapia Ocup USP 2008; 19(3): 176-182.

9. Costa YM, Porporatti AL, Stuginski BJ, Bonjardim LR, Conti PC. Additional effect of occlusal splints on the improvement of psychological aspects in temporomandibular disorder subjects: A randomized controlled trial. Arch Oral Biol 2015; 60(5):738-744.

10. Nettleton S. 'I just want permission to be ill': towards a sociology of medically unexplained symptoms. Soc Sci Med 2006; 62:1167-1178.

11. Barreto J. Nota da Tradutora. In: Derrida J. Torres de Babel. Belo Horizonte: Editora UFMG; 2002. p. 7-9.

12. Derrida J. Torres de Babel. Belo Horizonte: Editora UFMG; 2002. 
13. Biato ECL, Leitão CC. Suplementos de escrituras: de errâncias e destinos. Rev Polis Psique 2017; 7(1):149166.

14. Barsaglini RA, Biato ECL. Bilhetes/bereus como agenciamento para comunicar necessidades de saúde em penitenciária, Mato Grosso. In: Machado WK. Impactos das tecnologias nas ciências humanas e sociais aplicadas 5. Ponta Grossa: Atena Editora; 2019.

15. Nietzsche FW. Ecce homo: como alguém se torna o que é. São Paulo: Companhia das Letras; 1995.

16. Deleuze G. Nietzsche e a filosofia. Portugal: Rés Editora; 2001.

17. Marton S. Das forças cósmicas aos valores humanos. São Paulo: Brasiliense; 1990.

18. Marton S. Nietzsche, seus leitores e suas leituras. São Paulo: Editora Barcarolla; 2010.

19. Nietzsche FW. Aurora. São Paulo: Companhia das Letras; 2004.

20. Biato ECL. Oficinas de Escrileituras: Possibilidades de transcriação em práticas de saúde, educação e filosofia [tese]. Cuiabá: Universidade Federal de Mato Grosso; 2015.

21. Herzlich C. Saúde e doença no início do século XXI: entre a experiência privada e a esfera pública. Physis 2004; 14(2):383-394.

22. Lillrank A. Back pain and the resolution of diagnostic uncertainty in illness narratives. Soc Sci Med 2003; 57:1045-1054.

23. Anderson GC, Gonzalez YM, Ohrbach R, Truelove EL, Sommers E, Look JO. The research diagnostic criteria for temporomandibular disorders. Vi: Future directions. J Orofac Pain 2010; 24(1):79-88.

24. Monteiro SB. Quando a pedagogia forma professores. Uma investigação otobiográfica [tese]. São Paulo: USP; 2004.

25. Derrida J. Otobiografías. La enseñanza de Nietzsche y la política del nombre propio. Buenos Aires: Amorrortu; 2009.

26. Nietzsche FW. O nascimento da tragédia ou Helenismo e pessimismo. $2^{\text {a }}$ ed. São Paulo: Companhia das Letras; 2006.

27. Rollman GB, Gillespie JM. The role of psychosocial factors in temporomandibular disorders. Curr Rev Pain 2000; 4:71-81.

28. Nietzsche FW. Fragmentos póstumos [Internet]. [acessado 2012 fev 16]. Disponíveis em: www.nietzschesource.org.
29. Shueb SS, Nixdorf DR, John MT, Alonso BF, Durham $\mathrm{J}$. What is the impact of acute and chronic orofacial pain on quality of life? J Dent 2015; 43(10):1203-1210.

30. Nietzsche FW. Humano, demasiado humano I. São Paulo: Companhia das Letras; 2005.

31. Ferreira J. O corpo sígnico. In: Alves PC, Minayo MCS. Saúde e Doença: um olhar antropológico. Rio de Janeiro: Fiocruz; 1994. p. 174.

32. Barthes R. O prazer do texto. São Paulo: Perspectiva; 1987.

33. Eaves ER. "Just Advil": Harm reduction and identity construction in the consumption of over-the-counter medication for chronic pain. Soc Sci Med 2015; 146(1):147-154.

34. Pastore G, Goulart D, Pastore P, Prati A, Moraes M. Self-medication Among Myofascial Pain Patients: A Preliminary Study. Open Dent J 2018; 12:347-353.

35. Lin S, Wu S, Huang H, Pulmão F, Chi T, Yang J. Can a 10-Minute Questionnaire Identify Significant Psychological Issues in Patients With Temporomandibular Joint Disease? J Oral Maxillofac Surg 2017; 75(9):1856-1865.

36. Kahlo F. El diario de Frida Kahlo. Un íntimo autorretrato. Mexico: La vaca independiente; 1995.

37. Teixeira A. O Teatro da Cura Cruel. Interface (Botucatu) 1999; 3(5):187-192.

38. Moreira A. Nietzsche e Espinosa: fundamentos para uma terapêutica dos afetos. Cad Espinosanos 2010; 24:141-165.

39. Biato ECL, Costa LB, Monteiro SB. Pequenas e grandes saúdes: uma leitura nietzschiana. Cien Saude Colet 2017; 22(3):965-974.

40. Canguilhem G. O normal e o patológico. Rio de Janeiro: Forense Universitária; 2002.

Artigo apresentado em 03/12/2019

Aprovado em 07/07/2020

Versão final apresentada em 09/07/2020

Editores-chefes: Romeu Gomes, Antônio Augusto Moura da Silva 